\title{
Assess the Extinction Risk of Mountain Endemic Plants in Egypt Under the Current Climatic Condition: A Case Study of Endemic Silene Species
}

\author{
Karim Omar and Ibrahim Elgamal
}

\section{ABSTRACT}

The process of developing a conservation programme for endemic plant species, in particular those with a small geographical size in mountain ecosystems, whether in situ of ex situ, is a very complex matter, especially if data on the state of the environment and conservation are unavailable. Silene leucophylla and Silene oreosinaica are perennial plants endemic to St. Catherine Protected Area (SCPA), which locate at South Sinai, Egypt. For long time, the second species has not been observed in the field. As a result, the purpose of this study was to increase understanding of the two species' ecological and conservation statuses by: The first step is to confirm their existence on the ground; the second step is to determine the present ecological and conservation conditions through an extinction risk assessment by using IUCN Red List methodology; and the third step is the use of Species Distribution Model (SDM) to locate and extract current appropriate habitat suitability. The field research, which was conducted between March to December 2017, resulted in building knowledge of the current distribution, characteristics of current species populations, and status of ecology and habitat, in addition to identifying the main threats. Both species have been recorded in $\mathbf{2 0}$ major sites, in a very restricted area, particularly in a high mountain region (19 sites of Silene leucophylla and 3 sites of $S$. oreosinaica), with Extent of Occurrence about $468.2 \mathrm{~km}^{2}$ for Silene leucophylla and $24.5 \mathrm{~km}^{2}$ for $S$. oreosinaica. The population size was very small and fragmented and the extreme drought and overgrazing clearly affected both species. Based on the collected data, the extinction risk was calculated as Critically Endangered for $S$. oreosinaica and as Endangered for S. leucophylla according to IUCN Red List. For both species, appropriate habitat is concentrated in the high mountain ranges in the central north section of the SCPA, according to SDM. For Silene leucophylla, a presence probability of $20.5 \mathrm{~km}^{2}$ was anticipated, whereas for $S$. oreosinaica, a presence probability of $62.1 \mathrm{~km}^{2}$ had been predicted. Conservation methods are advocated both in situ (via recovery) and ex situ (by seed collecting and storage, awareness building, and grazing control).

Keywords: conservation management; endemic plants; IUCN Red List; mountain habitat; poorly known species; Silene leucophylla; Silene oreosinaica; Species Distribution Models.

\section{INTRODUCTION}

Biodiversity conservation is a well-established goal at global level, but sadly, amid the efforts of conservationists over the last decades, biodiversity poses significant challenges and appears to be lost when it comes to adopting rates at global level [1], [2]. We lack knowledge on the distribution of species in numerous nations [3], [4] due to bias to collection of species, inappropriate techniques for sampling, lack of resources and facilities for research, and species identification and definition difficulties [5]. As a consequence, incomplete and non-representative data frequently impede successful conservation of biodiversity where the process of bridging these gaps for governments in developed countries is a daunting challenge [6]-[9]. One of
Published Online: September 12, 2021

ISSN: 2684-5199

DOI: $10.24018 /$ ejbio.2021.2.5.261

\section{Karim Omar*}

Nature Conservation Sector, Ministry of

Environment, Cairo, Egypt.

United Nation Development Program

(UNDP), Cairo, Egypt.

(e-mail: kariemomar@gmail.com)

Ibrahim Elgamal

Nature Conservation Sector, Ministry of Environment, Cairo, Egypt.

(e-mail: ibrahim_abdelrafee@yahoo.com)

*Corresponding Author the reasons why human activity is having a greater influence on biodiversity is a lack of knowledge about the distribution, present ecology, and conservation status of species, which is required for conservation management [8], [9].

When deciding whether to dedicate attention and precious resources to the conservation of a certain species, one of the most essential variables to evaluate is the serious risk of extinction [8]. Although the extinction risk is evidence that the species needs attention both inside and outside the site, it is not the only factor in determining conservation priorities [10]-[12]. In order to determine the priorities, a comprehensive survey must be made that includes knowledge of the environmental, social and economic situation, and the decision to save in the end is based on mutual discussion [9]. 
Many systems employ a combination of quantitative and qualitative characteristics. The IUCN Red List Categories and Criteria are the most important and frequently used technique for assessing worldwide extinction risk. A species' vulnerability to extinction is heightened when it has a limited geographic range [13]. Generally, if the size of the distribution of a species decreases, the risk of extinction increases [14]. On the IUCN Red List, most of the critically endangered plant taxa are limited to tiny ranges. Fontaine et al. [15], and Omar \& Elgamal [9] found that the most at risk of extinction is by far the small-range limited endemics. Many methods, such as the IUCN Red List and Species Distribution Models (SDMs), are extensively used today to assess the conservation status of individual taxa and define scenarios for appropriate nature conservation [9]. The IUCN Red List categories and criteria are largely regarded as the most thorough and trustworthy instrument available for assessing the worldwide danger of species extinction [16][19]. Data from the Red List (including habitat criteria, threats, and proposed conservation measures) may be used to identify and aid in the development of conservation initiatives and recovery plans for species that require special conservation measures [20], [9].

Despite the scarcity of geographic data, SDMs are a very effective tool for anticipating the geographical distribution of little-known species [21], [9]. It is a powerful tool that uses computer algorithms to predict species distributions over space and time using environmental data. There is clear evidence that SDMs lead to accurate depiction of distributions even with little data [22]. The main points are that SDMs for single or multiple species are built on the basis of survey data over a variety of environmental variables. The technique identifies key environmental factors for each species or population and then extrapolates from known survey areas to the whole target region. These statistical models depict the anticipated distribution as either a binary function or a probability landscape [23]. It has recognized as an effective technique in spatial ecology, conservation, and land management [24]-[27], [21], [9]. SDMs are currently used by conservationists to rehabilitate or monitor multiple species from extinction [28]-[31], [9].

Many endemic species rely on mountain habitat for their survival [32]. Over-harvesting for fuel and medicinal plants usage and trading as well as over-grazing, urban growth and quarrying have led to poor vegetation cover, species extinction and soil fertility deterioration in dry mountain ecosystems such as Sinai in Egypt owing to uncontrolled human activities due to a lack of data [33]. As we know, the endemic species is the ecological status of species where the species is unique and exclusive to a particular geographical region. Consequently, the first extinction candidates can be predicted for endemic species characterized by limited spatial distribution [13], [34], [35]. The St. Catherine Protected Area (SCPA), city in Southern Sinai, Egypt, is a mountain ecosystem that is inhabited to 17 endemic plant species [36]. It is also considered one among Egypt's most valuable protected areas in terms of endemic species, topography, culture, and legacy. Most of these taxa are crucial to Egyptian biology, cuisine, heritage, and medicinal capacities [37]-[39].

At regional level, there has been a loss in plant variety in the southern and eastern Mediterranean, according to
Valderrábano et al. [40]. According to this report, in order to stem the loss of biological diversity, it is necessary to develop and update Red lists of threatened species, which serve as a useful source of information on extinction risk, threats, and trends. At the national level, the Egyptian Ministry of Environment updated the National Biodiversity Strategy and Action Plan (NBSAP) for the years 2015-2030, with one of its goals being the conservation and management of endemic and endangered species in accordance with international standards while also meeting Aichi Targets 1 and 12. Omar [41]-[45], [9] evaluate the extinction risk of several endemic species inside SCPA using the IUCN Red List Categories and Criteria in the field of endemic plant conservation planning in Sinai, Egypt (fine-scale).

Caryophyllaceae is one of the most commonly represented families of endemic species in the Sinai Peninsula. The Silene L. genus consists of approximately 23 sections and 700 species worldwide [46]. In Egypt, there are 29 species, 2 subspecies and 11 varieties [47] which are distributed throughout Egypt, especially in Sinai, where 19 species can be found.

SCPA has seven Silene species that grow in sporadic forms. These are S. arabica Boiss., Boiss., S. linearis Decne., S. villosa Forssk., S. odontopetala Fenzl var. congesta Boiss., $S$. schimperiana Boiss., $S$. oreosinaica Chowdhui, and $S$. leucophylla. The last two are SCPA endemic plants with little or no prior thorough research on their ecology and conservation conditions, particularly $S$. oreosinaica. This species is exceedingly uncommon and threatened [48]. It was recorded as a Schimper for the first time in 1835, then it was collected in 1982 and 1983 from Mount Catherine and the Wadi Ferran in South Sinai. Although many explorations and field studies have been undertaken in the South Sinai region, no sample of $S$. oreosinaica has been collected from this date until 2016 [49].

The two species are exposed to great threats, especially from overgrazing in the area, which leads to the destruction of the flowering organs and thus the plant loses the ability to produce seeds that support its propagation and survival. Detailed and accurate information about the spatial range, population dynamics, demography, habitats, threats, and applications of the target species must be gathered in order to establish an effective and sustainable conservation program (in situ and ex situ) for the target species. The lack of the basic information necessary to conserve these species, along with some of the threats already present in this area, will increase the risk of extinction. Therefore, the purpose of this study was to increase understanding of the two species' ecological and conservation statuses by: i) confirming their existence on the ground; ii) determine the present ecological and conservation conditions through an extinction risk assessment by using IUCN Red List methodology; and (iii) using Species Distribution Model (SDM) to locate and extract current appropriate habitat suitability.

\section{MATERIALS AND METHODS}

\section{A. Target Species}

Based on Boulos, [47], [50]; El Hadidi \& Hosni [51]; Hosny et al. [52]; Rabei et al. [49], [53]; Täckholm [54]. 
Silene leucophylla Boiss. It is a perennial plant with a woody root that can grow up to 30 Cylindrical stems with a $2-5 \mathrm{~cm}$ internode length. Base leaves oblong to spathulate, occasionally orbicular, $0.63 \mathrm{~cm}$ long, with sharp apex and whole edges, grouped in a rosette. It has opposing decussate, petiolate leaves with sharp apex and whole margins that are ovate to spathaulate in shape Flowering and fruiting times: Flowering season is March-April, while fruiting season is July-September. Slopes, terraces, and gorges are suitable habitats (rocky crevices). This species is rare and restricted to SCPA (South Sinai).

Silene oreosinaica Chowdhuri. Is a perennial with a woody structure at the base that can grow up to $25 \mathrm{~cm}$ long. Hairy, cylindrical stem with internodes up to $5 \mathrm{~cm}$ long. Basal leaves are lanceolate, $0.4-4.5 \mathrm{~cm} \times 0.1-0.9 \mathrm{~cm}$, grouped in a rosette form, with a sharp apex, complete edges, a symmetrical base, and are sessile. Cauline leaves are lanceolate, 0.4-2.5 $\times 0.1-0.2 \mathrm{~cm}$, opposite decussate with sharp apex, whole border, symmetrical base, and sessile. Racemes in the inflorescence, pedicle; pedicel length $0.5 \mathrm{~cm}$. Capsules are $0.8-1.2 \mathrm{~cm}$ length and oval in shape. Flowering occurs mostly in the spring months, from March to May, with a few exceptions in December and January. Fruiting occurs from July to October. Slope microhabitat is where the species may be found (Rocky crevices). Rare and unique to SCPA (southern Sinai).

\section{B. Study Area}

The area of this study is located inside the boundaries of SCPA which situated in the southern part of Sinai and is a part of the upper Sinai massif. The geographic range spread between $33^{\circ} 55^{\prime}$ to $34^{\circ} 30^{\prime}$ East and $28^{\circ} 30^{\prime}$ to $28^{\circ} 35^{\prime}$ North [55]. The SCPA encompasses nearly the whole mountain massif of southern Sinai, covering an area of $4350 \mathrm{~km}^{2}$. The SCPA includes one of the most magnificent and resource-rich regions in the Middle East. It has Egypt's highest mountains (St. Catherine Mountain, $2642 \mathrm{~m}$ ), which sustain a distinct collection of high-altitude ecosystems with a remarkably diversified fauna and flora and a reasonably high proportion of endemic species [56]. Because of the peculiar geology, geography, and climate of the mountains, the flora differs from that of the rest of Sinai [57]. SCPA is one of the most plant-diverse areas in the Middle East, accounting for 22 percent of Egyptian flora (472 plant species) [56]-[59] along with more than 30 percent of total Egypt's endemic plant species [36]. South Sinai's mountains have been identified as among the one of highest levels of plant variety in the Middle East's Saharo-Sindian (Irano-Turanian) area. It has been designated as an Important Plant Area (IPA), as well as an Important Bird Area (IBA). According to past records and a survey of the literature, the majority of plant endemics are found in high mountain areas (500 to $2600 \mathrm{~m}$ ), which will be the focus of our work. (Fig. 1).

The SCPA is located in the arid North African desert region and has a Saharo-Mediterranean climate. Even though the altitude influences the temperature regime, summer weather is relatively hot, with a mean maximum temperature of 36 degrees Celsius (August), while winters are noticeably cooler, with mean minimum temperatures of -7.8 degrees Celsius (February) in St Catherine Town and minus 20 degrees Celsius with wind chill. The annual precipitation would be less than $50 \mathrm{~mm}$ [8], [9]. Precipitation is intermittent but generally occurs between October and May, when severe severe flooding can occur following flash flooding; there are oscillations in precipitation since rainfall is not of annual nature; rather, 2 to 3 years or more without precipitation is normal. Because the relative humidity is low, often between 10 and $20 \%$ and rarely exceeding 50\%, prospective evaporation rates are quite high — in excess of $20 \mathrm{~mm} /$ day in August [9].

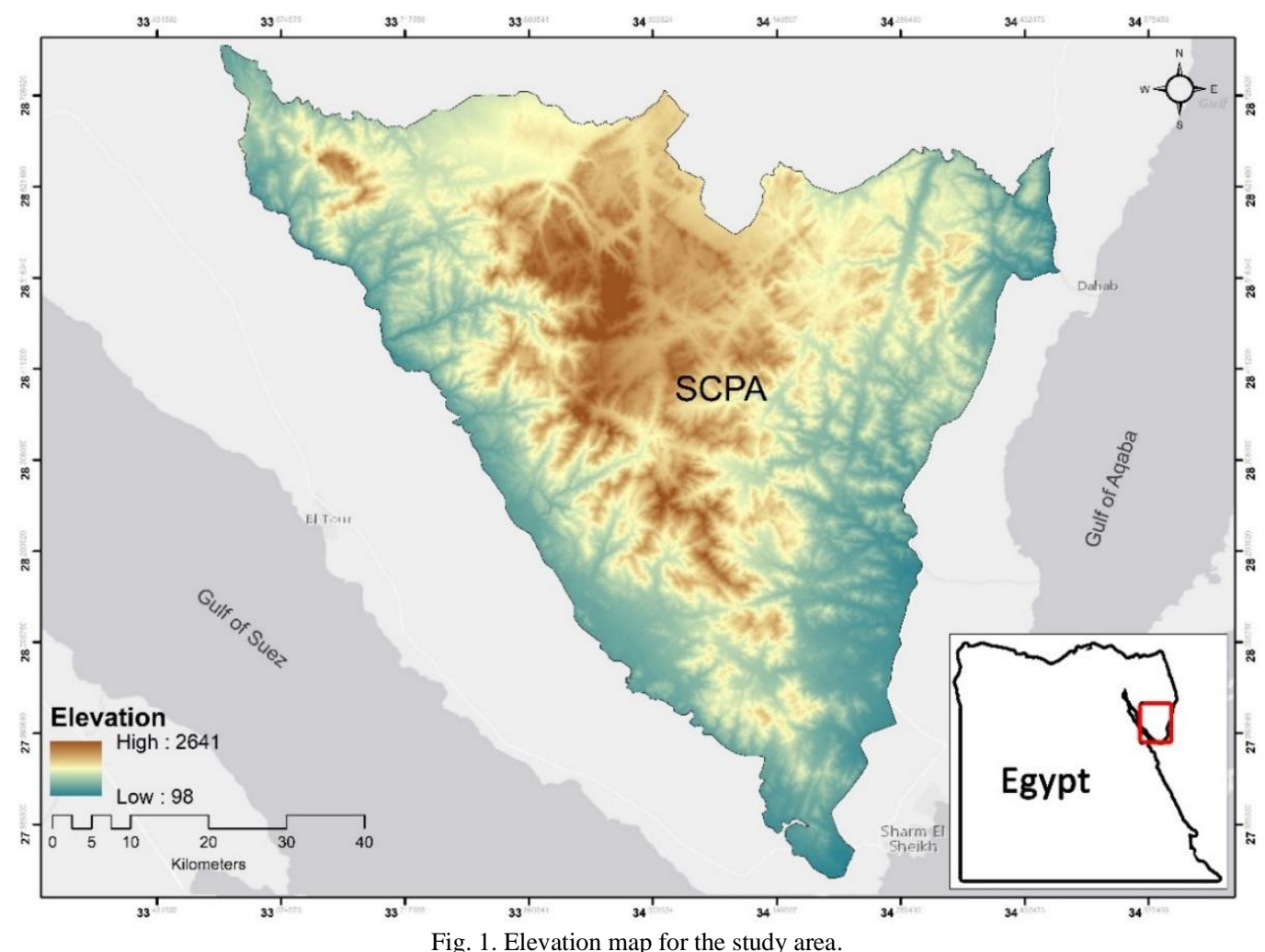




\section{Data Collection:}

\section{1) Species Presence Verification}

This research has been carried out between March and September of 2017. To know of the existence of target species in the field, a thorough investigation and assessment of all prior studies in the research area, scientific literatures, and national and international herbariums was performed. Given the scarcity of historical information on the distribution of targeted species, we concluded to fill out a survey on sites with available past data (especially for Silene oreosinaica) based on [49], and [59]-[61], as well as on identical sites (in terms of topography, soil type, micro-habitat). Using ArcGIS 10.4.1, historic locations were mapped, and comparable habitats were extracted. Based on prior study on the distribution of endemic plants in SCPA, we determined that all endemic plants are found in high mountain areas (the northern central part of the SCPA). The goal of the fieldwork is not so much to study the vegetation in the area as it is to provide a comprehensive description of the target spatial variability, range, and occupation across the environmental gradient in order to assess the Red List Status. So, utilizing Quadrat sampling approaches, we utilize a systematic sampling approach to capture local environmental gradients by putting 125 quadrates (Square Quadrate) with an area of $25 \mathrm{~m}^{2}$ in selected areas [62]. Historically sites were revisited, and once the target species was found, a quadrat was taken, and so on. Based on statistics, the attitudinal range for this study ranges from 500 to $2400 \mathrm{~m}$ and covers every microhabitat. Due to the sensitive nature and rarity of the two species, the local names of the sites were not utilized and were substituted with Site 1, 2, 3, and so on to minimize potential possible threat of species over-collection for science investigation.

\section{2) IUCN Red List Assessment}

We utilized the IUCN Red List Categories and Criteria: Version 3.1 to evaluate the current ecological and conservation conditions of these plants [63], and its guidelines [16]. In delivering the field results as a worldwide standard tool to collect the following data, criterion B. "Geographic range in the form of either B1 (extent of occurrence) AND/OR B2 (area of occupancy)" is used to gather the following information:

\section{1) Geographic Range}

During the field survey, the distribution of the two species inside SCPA was recorded. Using a Garmin 12 XL receiver, a GPS fix was acquired for the 125 quadrates in decimal degrees and datum World Geodetic System 1984 (WGS 84). The altitude was recorded as well as the fix to the fifth decimal digit. The study locations were plotted using ArcGIS 10.4.1. Based on the IUCN Standards and Petitions Committee [16], the number of locations where the species exists, the Extent of Occurrence (EOO), and the Area of Occupancy (AOO) were evaluated. EOO is defined as "the area contained within the shortest continuous imaginary boundary that can be drawn to encompass all the known, inferred, or projected sites of present occurrence of a taxon," whereas AOO is defined as "the area occupied by a taxon within its 'extent of occurrence,' excluding cases of vagrancy" (a grid size of $2 \times 2 \mathrm{~km}$ grid). The EOO and AOO were calculated and mapped using the Geospatial Conservation Assessment Tool.

\section{2) Population Characteristics}

The total number of individuals and mature individuals in each quadrate were counted to calculate the number of target species subpopulations and populations. For future comparisons, we obtained baseline data on the size of the local populations (population trend, fluctuations, fragmentation, and decline trend). The population size and number of mature individuals were estimated using the data accuracy and uncertainty levels given in the IUCN Standards and Petitions Committee [16].

\section{3) Habitats and Ecology}

Ideal habitat of the target species was documented in each quadrate using the IUCN Habitats Classification Scheme ver. 3.1 (https://www.iucnredlist.org/resources/classificationschemes). Within each quadrate, microhabitat (slope, wadi, terraces, gorge, cave) and elevational range were documented. The SCPA weather station was used to record climatic characteristics (Max. Temp., Min. Temp., and Perception) during the year 2017. Soil characteristics: One soil sample was taken from each quadrate (125 samples) as a profile of $0-30 \mathrm{~cm}$. Because soils in certain hilly areas were relatively thin, the maximum depth of soil samples ranged from 10 to $20 \mathrm{~cm}$. The majority of the soil samples were obtained from the quadrates under canopy of the studied plant species. According to Jackson [64], physical and chemical characteristics (texture, pH, ECs/ cm, T.D.S PPm, Water content percent, Organic matter percent $\mathrm{CaCO}_{3}$ percent, $\mathrm{Ca}^{++}$ meq/L, $\mathrm{Mg}^{++}$meq/L, $\mathrm{Na}^{+}$PPM, K ${ }^{+}$PPM, $\mathrm{HCO}_{3-}$ meq $/ \mathrm{L}, \mathrm{Cl}^{-}$ $\mathrm{meq} / \mathrm{L}$, and $\mathrm{SO}_{4-}-\mathrm{meq} / \mathrm{l}$ ) were examined. According to BraunBlanquet [65], vegetation parameters of target species such as density, cover, frequency, and related species were measured in each quadrat.

\section{4) Threats}

During the fieldwork, we documented all practices that may contribute to a decline in plant population trend, such as grazing, gathering, droughts, water abstraction, invasive plants, etc. [66]. Each threat's timing, scope, severity, and impact score were determined using the IUCN Threats Classification Scheme ver. 3.2 (https://www.iucnredlist.org/resources/classificationschemes).

\section{5) Conservation Requirements}

We have gathered all relevant data on past, present, and future activities directed at conserving these species through in situ or ex situ techniques in this section. A consultation conference was held with stakeholders (SCPA Administration, the local community, rangers, and the public at large) to identify conservation gaps and provide recommendations for best land management. The IUCN Classification Scheme was used to propose conservation activities, needs, and research needed to save the target species.

\section{6) Red List Category \& Criteria}

IUCN Red List Categories and Criteria Version 3.1 (Table 2.1/p. 16 [16]) were used to evaluate the degree of sensitivity 
of the target species to extinction based on the data gathered from the preceding phases.

\section{3) Species Distribution Model (SDM)}

\section{1) Environmental variables}

To identify the possible range of the target species using a prediction model, 113 and 20 occurrences of Silene leucophylla and $S$. oreosinaica, respectively, were utilized to build the prediction model. We evaluated at 22 environmental factors (19 bioclimatic and three topography) as possible predictors of target species habitat distribution [8], [9], [26], and [27]. These variables were selected based on their biological significance to target species distributions and prior habitat modeling studies [8], [9], [67]-[69]. The WorldClim database (http://www.worldclim.org/; [70]) was used to download a total of 19 bioclimatic variables, which are physiologically more relevant in defining a species' ecophysiological tolerances [71], [72], with a spatial resolution of 30 arc-second (approx. $1 \mathrm{~km}^{2}$ ). The Shuttle Radar Topography Mission provided elevation data at a resolution of $1 \mathrm{~km}^{2}$ (SRTM). Using the Spatial Analyst tool/surface in ArcGIS 10.4.1 software, the elevation data were utilized to create slope and aspect (all in degrees). Autocorrelation issues were resolved by removing duplicate presences on the scale of bioclimatic variables utilized in each $1 \times 1 \mathrm{~km}$ grid [73]. WGS 84 standard geographic coordinates in decimal degrees (to five decimal places) were used. After downloading the data from 1950 to 2000, the SCPA layer was removed using its boundary mask. Following that, extracted files were transformed to ASCII format for usage with Maxent program using ArcGIS 10.4.1.

All the 22 environmental variable combinations were evaluated for multi-collinearity using R-squared in linear regression analysis in SPSS ver. 25. Because topographic and bioclimatic factors were significantly associated $\left(R^{2} \geq 0.7\right)$, just those variables with limited association with other predictors were kept in this analysis, as recommended by Kalle et al. [76] and Omar \& Elgamal [8], [9]. For Silene leucophylla, a total of 11 environmental variables were selected in this study $\left(\mathrm{R}^{2}<0.7\right)$; elevation, aspect, mean diurnal range (max. temp - min. temp) (bio2), Isothermality $($ Bio2/Bio7) $\times 100($ bio3), mean temperature of driest quarter (bio9), mean temperature of warmest quarter (bio10), mean temperature of coldest quarter (bio11), precipitation of wettest month (bio13), precipitation of wettest quarter (bio16), precipitation of driest quarter (bio17), and precipitation of coldest quarter (bio19). For S. oreosinaica the previous environmental variables were selected except aspect and Isothermality $($ Bio2/Bio7) $\times 100$ (bio3) which showed high correlation with other variables.

\section{2) Modeling procedure}

We applied the maximum entropy distribution (Maxent) modelling methodology, which has already been proven to outperform a variety of modeling methods [8, [9], [21], [22], [26], [27], [69], [77], and may be successful even with small datasets [9], [78], [79]. For the studied area, it basically entails species presence data (not absence) and environmental variable (continuous or categorical) layers. We applied the publicly available Maxent program, version 3.3.3, which provides a probability of occurrence of the species that ranges from 0 (unsuitable) to 0.99 (best habitat appropriateness) on a scale of 0 (unsuitable) to 0.99 (best habitat suitability). A collection of 12 ASCII environmental layers and a csv file of species occurrence sites were used to create probability maps that predicted the possible distribution of the target species. A threshold independent Receiver-Operating Characteristic (ROC) analysis and Area Under Receiver-operating Characteristic Curve (AUC) values (range from $0.5=$ random to 1 = perfect discrimination) were used to evaluate Maxent's performance. The method either conducts 1000 repetitions of these operations or keeps going until convergence is reached (threshold 0.00001).

The relative importance of each environmental predictor was assessed in the models of each species using the percentage contribution of the Jackknife test, which is the best index for small sample sizes [9], [69]. The default logistic output format was selected, which is based on the possibility of suitable conditions, with values ranging from 0 to 1 . To avoid overfitting, we used 10 -fold cross validation in the "replicates" option to test the performance of the model of this species, as well as average of probability maps for habitat suitability [80], in which the occurrence data is randomly split into a class of similar groups, and models are created by leaving out each fold in turn. A total of $80 \%$ of the location point data was utilized for training, with the remaining $20 \%$ used to evaluate the model's prediction capabilities. The Maxent text result output has been used to extract the average and standard deviation values for training and test AUC for the ten models. The ASCII output map for each species was loaded into ArcGIS 10.4.1, where the prediction models of habitat suitability were divided into four classes based on Choudhury et al. [81], and Omar \& Elgamal [9]; 0.71 High Probability, 0.70-0.31 Moderate Probability, $0.30-0.11$ Low Probability, and 0.10 very low to unsuitable for the existence of the species.

\section{RESUlts}

\section{A. Species Presence Verification}

It was confirmed that the two species (particularly Silene oreosinaica) existed and were documented within the SCPA in high mountain regions after a comprehensive fieldwork of more than 50 locations (historical sites and high mountain areas). Where they were recorded at 20 sites (19 sites for Silene leucophylla and 3 sites for S. oreosinaica - where the two species share to sites) (Fig. 2).

\section{B. IUCN Red List Assessment}

\section{1) Geographic Range}

In southern Sinai, Egypt, Silene leucophylla and $S$. oreosinaica are endemic to the SCPA. S. leucophylla and $S$. oreosinaica have a limited altitude range of 900 to 2300 meters, respectively. Based on GeoCAT tool, Silene leucophylla and $S$. oreosinaica EOO are $468.271 \mathrm{~km}^{2}$ and $24.547 \mathrm{~km}^{2}$, and AOO are $84 \mathrm{~km}^{2}$ and $12 \mathrm{~km}^{2}$, respectively (Fig. 3 and 4). A distinct distribution of Silene leucophylla may be found in the High Mountains Area and Serbal Mountain, both of which span from north to south When it comes to the distribution of $S$. oreosinaica (High Mountains Area and Wadi Feiran) extended from east to west SCPA. It was recorded that Sites No. 19, 15, and 11 are the most sites 
where S. leucophylla frequently exists, while Sites No. 16 and 15 are the most for $S$. oreosinaica (Table I).

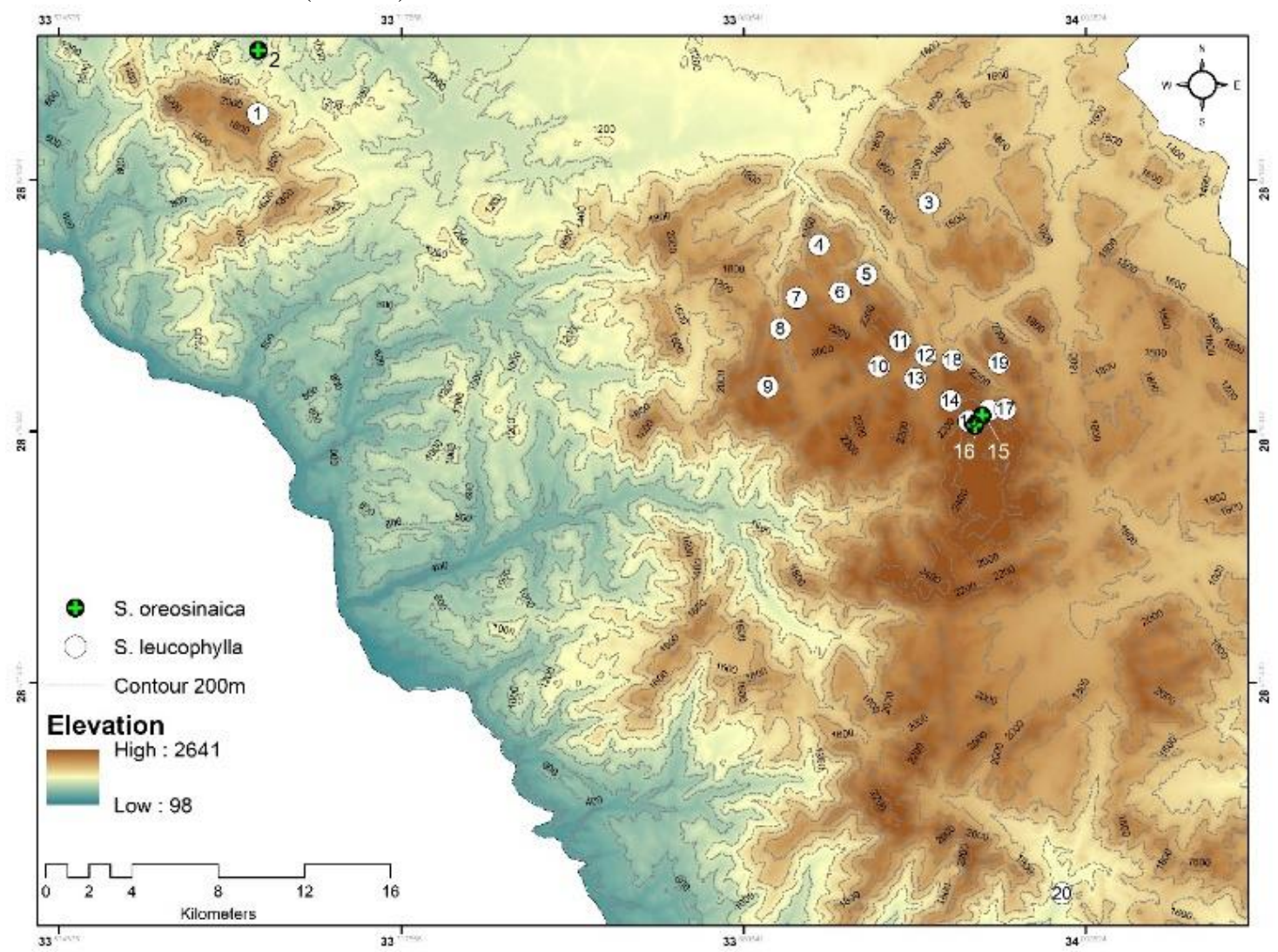

Fig. 2. Main subpopulations for Silene leucophylla and S. oreosinaica inside St. Catherine Protected Area.

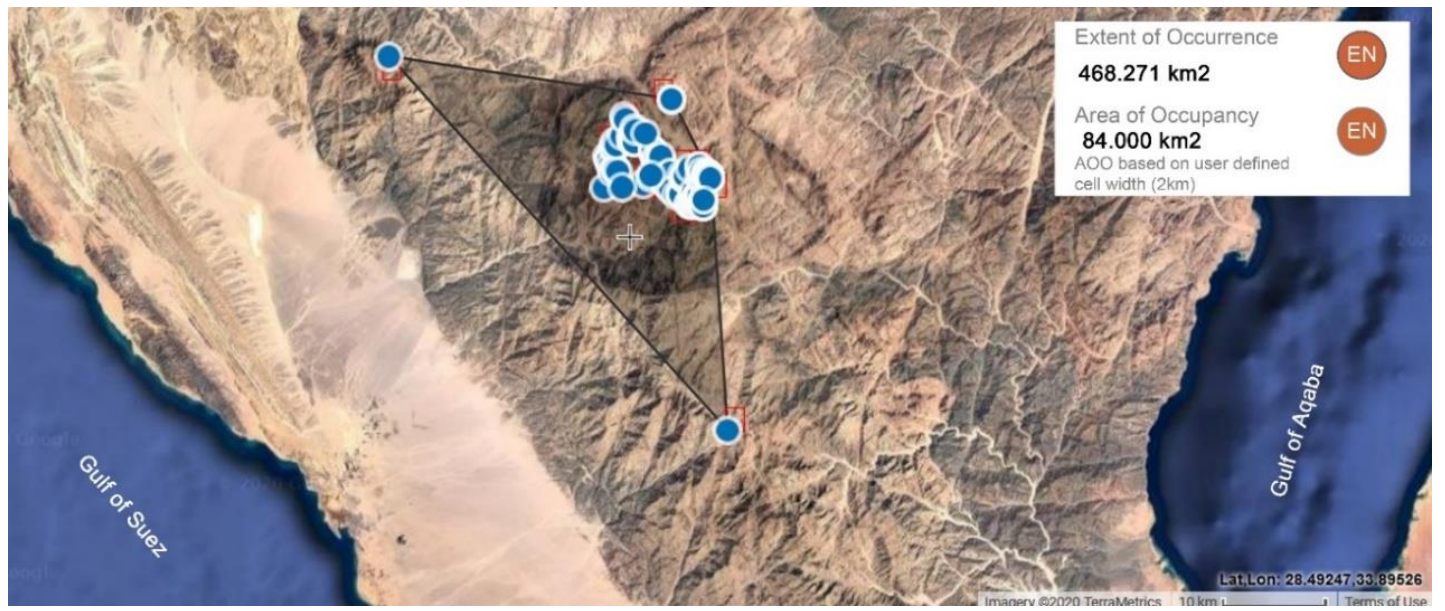

Fig.3. Distribution Range (EOO and AOO) of Silene leucophylla

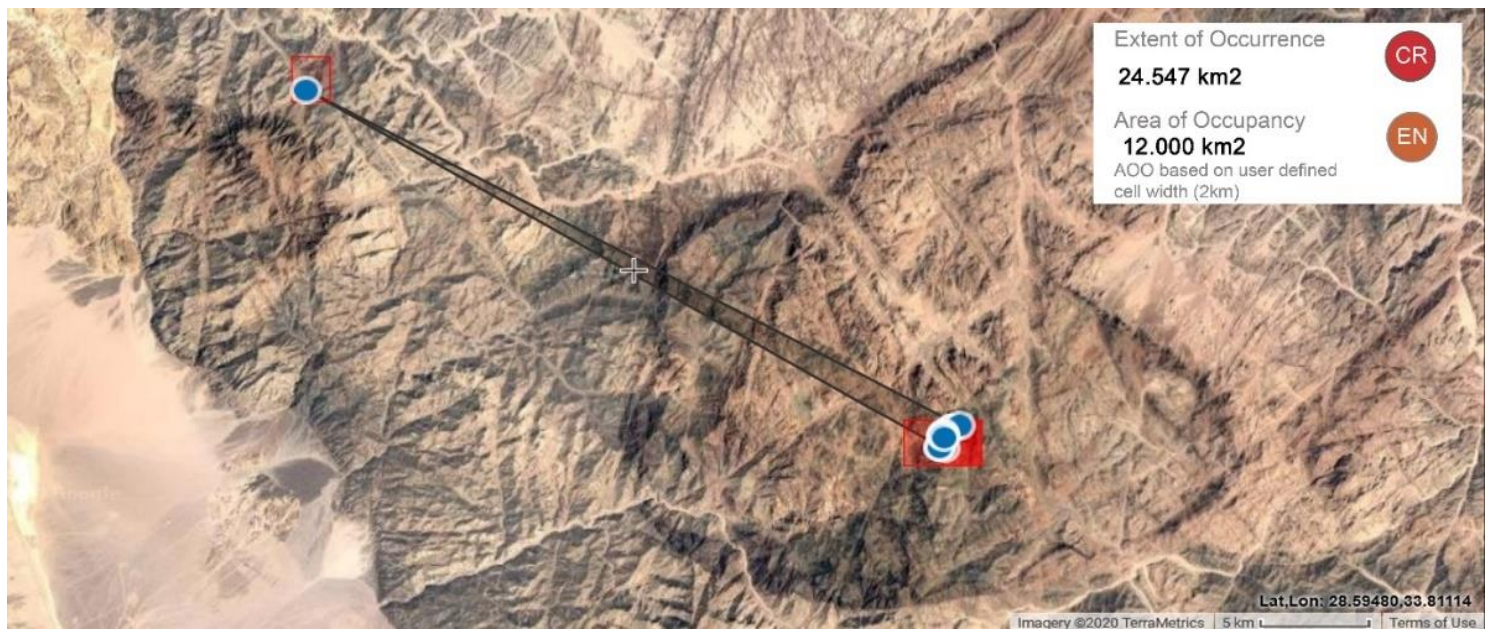

Fig.4. Distribution Range (EOO and AOO) of Silene oreosinaica. 
TABLE I: ECOLOGICAL CHARACTERISTICS FOR THE TARGET SPECIES SUBPOPULATIONS

\begin{tabular}{|c|c|c|c|c|c|c|c|c|c|}
\hline Subp. & Alt & Micro-Habitat & $\begin{array}{c}\text { No. of } \\
\text { Individuals }\end{array}$ & Frq. & $\begin{array}{l}\text { Spp. } \\
\text { C\% }\end{array}$ & $\begin{array}{l}\text { Veg. } \\
\text { C\% }\end{array}$ & Threat & Level & Aspect \\
\hline \multicolumn{10}{|c|}{ Silene leucophylla } \\
\hline 1 & 1741 & $\mathrm{~S}$ & 3 & 1 & 3 & 7 & $\mathrm{D}$ & 2 & $\mathrm{NE}$ \\
\hline 3 & 1610 & $\mathrm{~S}$ & 6 & 2 & 3.5 & 12.5 & $\mathrm{G}$ & 4 & $\mathrm{~N}$ \\
\hline 4 & 1775 & $\mathrm{~S}$ & 9 & 2 & 2.5 & 20 & $\mathrm{G}, \mathrm{D}$ & 1 & N, NW \\
\hline 5 & $1640-1800$ & S, G $(65,35 \%)$ & 6 & 3 & 3 & 15 & $\mathrm{G}, \mathrm{D}$ & 2 & NE, SE, SW \\
\hline 6 & $1750-1800$ & $\mathrm{~S}, \mathrm{~T}(95,5 \%)$ & 12 & 8 & 2 & 5 & $\mathrm{G}$ & 3 & $\mathrm{~N}, \mathrm{E}, \mathrm{SE}$ \\
\hline 7 & $1790-1920$ & S, G $(80,20 \%)$ & 18 & 5 & 3.5 & 10 & $\mathrm{G}, \mathrm{D}$ & 2 & NE, NW, W \\
\hline 9 & 2012 & $\mathrm{~S}$ & 7 & 1 & 3 & 5 & $\mathrm{D}$ & 4 & $\mathrm{~W}$ \\
\hline 10 & $1890-1990$ & $\mathrm{~S}, \mathrm{G}(75,25 \%)$ & 10 & 4 & 3 & 4 & $\mathrm{D}, \mathrm{G}$ & 3 & W, SE \\
\hline 11 & $1820-2150$ & $\mathrm{~S}, \mathrm{G}, \mathrm{T}(50,30,20 \%)$ & 30 & 10 & 1 & 20 & $\mathrm{G}, \mathrm{D}$ & 3 & $\mathrm{E}, \mathrm{NE}, \mathrm{N}$ \\
\hline 12 & $1760-1830$ & $\mathrm{~S}$ & 4 & 3 & 0.5 & 2 & G & 3 & SE, W, NW \\
\hline 13 & $1810-1860$ & $\mathrm{~S}$ & 7 & 4 & 0.5 & 2 & $\mathrm{D}, \mathrm{G}$ & 2 & NE, E, SW \\
\hline 14 & $1970-2050$ & $\mathrm{~S}$ & 21 & 5 & 1 & 3 & $\mathrm{D}$ & 2 & N, NE, NW \\
\hline 15 & $1890-2100$ & S, G $(75,25 \%)$ & 24 & 15 & 1 & 10 & $\mathrm{G}, \mathrm{D}$ & 3 & $\mathrm{NE}, \mathrm{NW}, \mathrm{N}, \mathrm{W}$ \\
\hline 16 & $2150-2260$ & $\mathrm{~S}$ & 10 & 5 & 0.5 & 3 & $\mathrm{G}, \mathrm{D}$ & 2 & NE, N, E, NW \\
\hline 18 & $1700-1850$ & $\mathrm{~S}, \mathrm{G}, \mathrm{T}(70,15,15 \%)$ & 29 & 6 & 3 & 20 & G, D & 4 & $\mathrm{~N}, \mathrm{NE}$ \\
\hline 19 & $1790-2050$ & $\mathrm{~S}, \mathrm{G}, \mathrm{T}(70,15,15 \%)$ & 52 & 21 & 1 & 5 & $\mathrm{D}, \mathrm{G}$ & 3 & $\begin{array}{c}\mathrm{N}, \mathrm{NE}, \mathrm{SW}, \mathrm{E}, \mathrm{W}, \mathrm{NW}, \\
\text { SE }\end{array}$ \\
\hline 20 & 900 & $\mathrm{~S}$ & 4 & 1 & 3 & 5 & $\mathrm{G}$ & 3 & W \\
\hline \multicolumn{10}{|c|}{ Silene oreosinaica } \\
\hline 2 & 950 & $\mathrm{~S}$ & 4 & 1 & 0.5 & 5 & $\mathrm{G}$ & 3 & $\mathrm{~N}$ \\
\hline 15 & $2050-2150$ & $\mathrm{~S}$ & 11 & 3 & 1 & 10 & $\mathrm{G}, \mathrm{D}$ & 3 & $\mathrm{~N}, \mathrm{NW}$ \\
\hline 16 & $2080-2350$ & $\mathrm{~S}$ & 30 & 8 & 1.5 & 10 & G & 3 & $\mathrm{~N}, \mathrm{NW}, \mathrm{NE}, \mathrm{E}$ \\
\hline
\end{tabular}

Microhabitat: S=Slope, G=Gorge, T=Terraces. Threats: $\mathrm{D}=$ Drought, G= Grazing. Levels: 1= Very Low and 5= Very High. Aspect: N: North, NE: Northeast, E: East, SE: Southeast, SW: Southwest, W: West, NW: Northeast.

\section{2) Population Information}

Both species have been found in more than one location, with Silene leucophylla being found in the Serbal Area, the High Mountains Area, and Wadi Isla, and Silene oreosinaica being found in the High Mountains Area and Wadi Feiran. The majority of Silene leucophylla and S. oreosinaica subpopulations are tiny to extremely small (19 and 3 subpopulations, respectively), with individual plants appearing sporadically in space in very few clusters where the soil is rocky. The entire worldwide population size for Silene leucophylla is estimated to be 1500-3000 mature individuals and 200-350 for $S$. oreosinaica. Taking the mountain barriers into consideration, there are obviously distinct 19 subpopulations for Silene leucophylla (Sites No. 1, 3-20) and 3 (Sites No. 2, 15) for S. oreosinaica (Fig. 2), and the number of mature individuals varies amongst subpopulations, ranging from 3 to 52 for Silene leucophylla and 4 to 30 for $S$. oeosinaica (Table I). Due to a lack of historical data, it is impossible to determine population trend, fluctuation, and loss rate. Because of the physical features of the area and the presence of natural barriers from the mountains, the population of the target species is visibly fragmented. The target species is spread between two specific areas (Fig 2), and the impacts of one risk will be perceived separately by the two areas: hence, the population is essentially split in two. Sites 19, 11, 18, and 17 had the highest density of Silene leucophylla, whereas Sites 16 and 15 have the highest density of $S$. oreosinaica (Table I).

\section{3) Habitat and Ecology}

According to the IUCN Habitats Classification Scheme, Silene leucophylla and S. oreosinaica are found in rocky mountain and desert habitats. During the field study, Silene leucophylla was found to be primarily restricted to mountain slopes, namely deep mountain cracks with granite hard terrain of mountain areas ( $80 \%$ of reported cases sites), with a minor presence in both gorges (15\%) and terraces (5\%). (Fig. 5).
Silene oreosinaica was found to be limited to slopes (100 percent of total points measured) (Fig. 6).

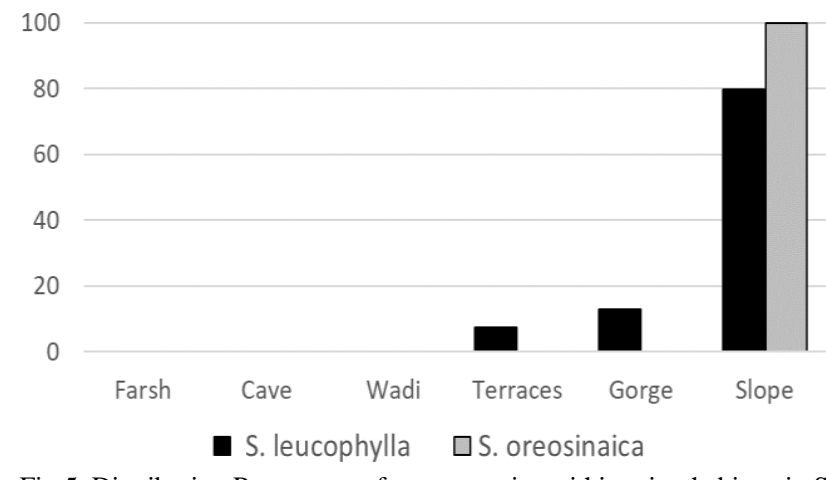

Fig.5. Distribution Percentage of target species within microhabitats in St. Catherine Protected Area.

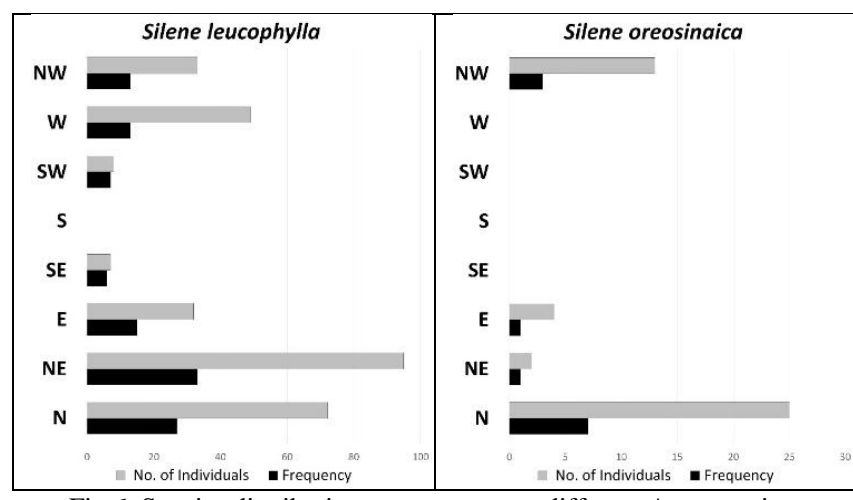

Fig.6. Species distribution patterns among different Aspect ratios.

Using topography as a key factor for plant dispersal, particularly on mountains, it has been discovered that Silene leucophylla are distributed in all aspects except South, and flat with most frequent in Northeast (29\%) and North (24\%). While $S$. oreosinaica recorded only in aspects North, Northeast, Northwest and East with most frequent in North $(57 \%)$ and Northeast (28\%) (Fig. 6). The optimal elevation 
ranges for the distribution of Silene leucophylla (based on species frequency) were discovered to be between 1800 to $2100 \mathrm{~m}$, whereas $S$. oreosinaica ranges from 2000 to $2350 \mathrm{~m}$.

Basing on the weather station data in St. Catherine in 20092017, average minimum temperatures for the coldest month were $-10.5^{\circ} \mathrm{C}$, while maximum temperatures for the warmest month were $34^{\circ} \mathrm{C}$. As a result of the height gradient in this area, the climate varies, with Mt. St. Catherine (Egypt's highest peak at $2641 \mathrm{~m}$ ) having the coldest temperature in the Sinai Peninsula. Between 2009 and 2017, the average annual precipitation in the dry environment was 30.3 millimeters, some of it snow, although there is a significant deal of fluctuation between years, with up to 300 millimeters in any one year, generally between October and May. The average annual relative humidity is 42 percent (from 2009 to 2017), and potential evaporation rates are quite high, exceeding 20 $\mathrm{mm}$ /day in August.

Both species are distributed in rocky slope soil where soil texture is loamy Sand to sandy. Alkaline and non-saline to slightly saline soil ( $\mathrm{pH} 7.1-8.9)$. Low water content and medium content of cation-exchange capacity (CEC), and essential nutrients. Electrical Conductivity (E.C. $\mu \mathrm{s} / \mathrm{cm}$ ) showed a wide range of variation in the different locations in SCPA with a range between 72 to $2940 \pm 399$ for Silene leucophylla and from 220 to $1086 \pm 242 \mu \mathrm{s} / \mathrm{cm}$ for $S$. oreosinaica. The same is true for Total Dissolved Solids (T.D.S) (Table II).

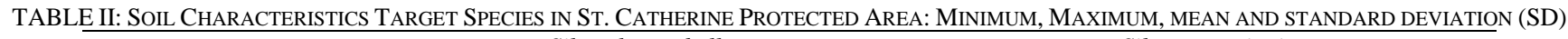

\begin{tabular}{ccccccccc}
\hline \multirow{2}{*}{ Variable } & \multicolumn{4}{c}{ Silene leucophylla } & \multicolumn{4}{c}{ Silene oreosinaica } \\
\cline { 2 - 9 } & Max. & Min. & Mean & Std. Deviation & Max. & Min. & Mean & Std. Deviation \\
\hline $\mathrm{pH}$ & 8.9 & 7.1 & 8.2 & 0.4 & 8.4 & 7.1 & 7.7 & 0.4 \\
T.D.S PPm & 1730 & 34.62 & 165.7 & 221.3 & 598 & 98 & 256.8 & 136.3 \\
$\mathrm{EC} \mu \mathrm{s} / \mathrm{cm}$ & 2940 & 72 & 328.7 & 399.9 & 1086 & 220 & 498.9 & 242.4 \\
Org. matter\% & 17.08 & 0.23 & 4.5 & 3.9 & 4.41 & 0.2 & 2.9 & 1.3 \\
water content & 32 & 0.08 & 1.4 & 3.6 & 6.9 & 0.31 & 1.5 & 1.9 \\
$\mathrm{CaCO}_{3} \%$ & 47 & 2.5 & 20.4 & 9.0 & 47 & 14.5 & 27.0 & 12.7 \\
$\mathrm{Ca}^{++}$meq/L & 50 & 1 & 11.4 & 11.0 & 34 & 3 & 17.0 & 11.7 \\
$\mathrm{Mg}^{++}$meq/L & 52.5 & 0.3 & 6.0 & 8.5 & 18.5 & 3 & 8.2 & 5.8 \\
$\mathrm{Na}^{+} \mathrm{PPM}$ & 65 & 9.2 & 26.2 & 11.9 & 41.39 & 15 & 34.7 & 7.4 \\
$\mathrm{~K}^{+} \mathrm{PPM}$ & 80.01 & 9.11 & 29.4 & 14.8 & 41.39 & 10.7 & 34.1 & 8.6 \\
$\mathrm{HCO}_{3}^{-}$meq/L & 20 & 4 & 10.1 & 3.6 & 18.4 & 7.5 & 12.3 & 3.2 \\
$\mathrm{Cl}^{-}$meq/L & 52.25 & 2.25 & 7.8 & 6.9 & 15 & 2.9 & 9.4 & 4.7 \\
$\mathrm{SO}_{4}^{--}$meq/l & 160 & 3 & 49.6 & 30.3 & 108 & 6.2 & 63.8 & 36.0 \\
\hline
\end{tabular}

In the slope microhabitat, the two target species were mostly found between mountain crevices and joints between surrounding rocks. It has been recorded that the most dominant species associated with Silene leucophylla are Gallium setaceum Lam., Chiliadenus montanus (Vahl) Brullo., Ballota undulata (Fresen.) Benth., and Micromeria serbaliana Danin \& Hedge. While Scrophularia libanotica Boiss., Tanacetum sinaicum (Fresen.) Delile ex Bremer and Humphries, and Micromeria serbaliana Danin \& Hedge are the most dominant species associated with $S$. oreosinaica.

\section{4) Threats}

Silene leucophylla and S. oreosinaica are recorded to be stressed by extreme drought. Rather than they recorded to be highly affected to heavy grazing. Sites No. 18, 17, 15, 3, and
9 are the most affected by overgrazing. During the fieldwork, 12 individuals (4\% of the total recorded individuals) were recorded as dead or dry from Silene leucophylla and 5 dead individuals ( $11 \%$ of the total recorded individuals) from Silene oreosinaica were recorded as a result from drought. Many studies have revealed that endemic plants in the SCPA are susceptible to significant disturbance as a result of anthropogenic such as over-collection (for medicinal or fuel use), overgrazing (goats, camels, feral donkeys), and uncontrolled scientific research (Destructive consumption through continuous collection for research especially collection of seeds). Table III contains a complete list of risks classified according to the IUCN classification scheme.

TABLE III: THREATS ON THE TARGET SPECIES BASED ON IUCN THREATS CLASSIFICATION SCHEME

\begin{tabular}{|c|c|c|c|c|c|}
\hline $\begin{array}{c}\text { IUCN } \\
\text { Code }\end{array}$ & Threat & Timing & Scope & Severity & Impact Score \\
\hline 2.3 .1 & $\begin{array}{c}\text { Agriculture \& aquaculture -> Livestock farming \& } \\
\text { ranching -> Nomadic grazing }\end{array}$ & Ongoing & Whole (>90\%) & $\begin{array}{l}\text { Causing/Could cause } \\
\text { fluctuations }\end{array}$ & High Impact: 9 \\
\hline 6.1. & $\begin{array}{c}\text { Human intrusions \& disturbance }->\text { Recreational } \\
\text { activities }\end{array}$ & Ongoing & Minority $(<50 \%)$ & $\begin{array}{l}\text { Causing/Could cause } \\
\text { fluctuations }\end{array}$ & Low Impact: 5 \\
\hline 7.2.5. & $\begin{array}{c}\text { Natural system modifications }->\text { Dams \& water } \\
\text { management/use }->\text { Abstraction of ground water } \\
\text { (domestic use) }\end{array}$ & Ongoing & Whole $(>90 \%)$ & $\begin{array}{l}\text { Slow, Significant } \\
\text { Declines }\end{array}$ & High Impact: 9 \\
\hline
\end{tabular}

\section{5) Species Distribution Model (SDM)}

The success rates of model performance for the Maxent model in this study was high, where training AUC 0.97 (0.96$0.99) \pm 0.008$ and test AUC $0.96 \pm 0.03$ for Silene leucophylla and training AUC $0.94(0.92-0.99) \pm 0.01$ and test AUC $0.97 \pm 0.02$ for $S$. oreosinaica. The most appropriate habitat for Silene leucophylla was projected to be in the middle northern and northeastern sections of SCPA, with the maximum suitability in the High Mountains and Serbal areas (Fig. 7), and its distribution is very fragmented due to mountain barriers. The scenario was different in the $S$. oreosinaica model, which was bigger and more linked. The species was seen to cover a large region of SCPA, with the most appropriate environment expected to be in the north and 
central sections of SCPA, with the maximum suitability in the High Mountains and Wadi Isla areas.

The internal jackknife test of variable contribution in the Maxent model revealed that precipitation of the driest quarter (Bio 17) and precipitation of the coldest quarter (Bio 19) had the largest mean contributions to the variables that affect the distribution of Silene leucophylla in SCPA (Table IV). While precipitation in the driest quarter (Bio17) and mean temperature in the driest quarter (Bio 9) have the largest mean contributions to the factors that influence the distribution of $S$. oreosinaica. Table IV presents a heuristic assessment of the proportional contributions of environmental factors to the Maxent model. To calculate the estimate, the increase in regularized gain is added to the contribution of the relevant variable in each iteration of the training process.
It was discovered that the probable distribution of Silene leucophylla covers an area of $287.9 \mathrm{~km}^{2}$ (6.6 percent) of the entire SCPA region $\left(4350 \mathrm{~km}^{2}\right)$. This region was classified as follows: $20.5 \mathrm{~km}^{2}$ high probability $(\geq 0.71), 157 \mathrm{~km}^{2}$ moderate probability $(0.70-0.31)$, and $138 \mathrm{~km}^{2}$ low probability $(0.30$ $0.11)$; the rest of SCPA was designated as inappropriate (4034 km² -92.7 percent). In the case of $S$. oreosinaica, the potential distribution covers an area of $1182.9 \mathrm{~km}^{2}(27.1$ percent) of the entire SCPA area $\left(4350 \mathrm{~km}^{2}\right)$. This region was classified as follows: $62.1 \mathrm{~km}^{2}$ high probability, $309.8 \mathrm{~km}^{2}$ moderate probability, and $811 \mathrm{~km}^{2}$ low probability; the remainder of SCPA was reported as inappropriate $\left(3166.7 \mathrm{~km}^{2}-72.7 \%\right)$.

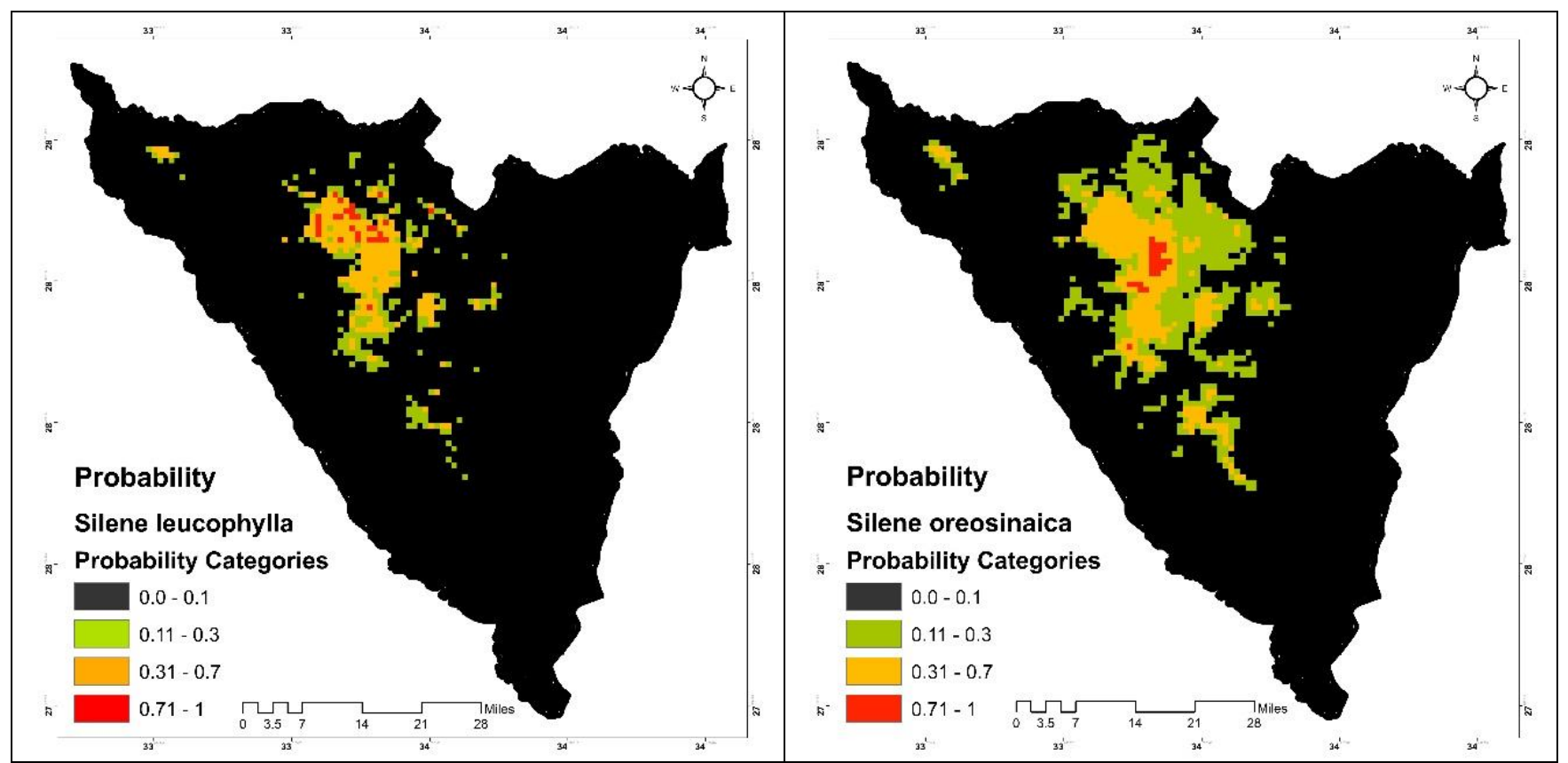

Fig. 7. Potential distribution map for Silene leucophylla and S. oreosinaica in SCPA.

TABLE IV: SELECTED ENVIRONMENTAL VARIABLES CONTRIBUTIONS FOR MODELING SILENE LEUCOPHYLLA AND S. OREOSINAICA IN THE STUDY AREA

\begin{tabular}{|c|c|c|c|}
\hline Variable & Code/Unit & S. leucophylla contribution (\%) & S. oreosinaica contribution (\%) \\
\hline Elevation & Elev $(\mathrm{m})$ & 0.6 & 3.6 \\
\hline Aspect & AS (degrees) & 5.5 & - \\
\hline Mean diurnal range ( $\max$. temp - min. temp) & Bio2 $\left({ }^{\circ} \mathrm{C}\right)$ & 2.6 & 0.3 \\
\hline Isothermality $(\mathrm{Bio} 2 / \mathrm{Bio} 7) \times 100$ & Bio3 & 0.1 & - \\
\hline Mean temperature of driest quarter & Bio9 $\left({ }^{\circ} \mathrm{C}\right)$ & 1 & 11.2 \\
\hline Mean temperature of warmest quarter & $\operatorname{Bio} 10\left({ }^{\circ} \mathrm{C}\right)$ & 1 & 7.8 \\
\hline Mean temperature of coldest quarter & Biol1 $\left({ }^{\circ} \mathrm{C}\right)$ & 0.4 & 1.8 \\
\hline Precipitation of wettest month & $\operatorname{Bio} 13(\mathrm{~mm})$ & 2.4 & 3.6 \\
\hline Precipitation of driest quarter & $\operatorname{Bio} 17(\mathrm{~mm})$ & 66.4 & 52.3 \\
\hline Precipitation of coldest quarter & Bio19 (mm) & 19.3 & 7.8 \\
\hline
\end{tabular}

Note: (-) variable not used in the model.

\section{DISCUSSION}

In this study, if we focus on the details of the geographical distribution of the target species, we will notice that the geographical distribution, whether in terms of extent or occupancy, is very small and largely fragmented due to the topography of the region and the elevations gradient. Where were recorded that Silene leucophylla and S. oreosinaica EOO are $468.2 \mathrm{~km}^{2}$ (10\% of SCPA area), and $24.5 \mathrm{~km}^{2}(0.5 \%$ of SCPA area), and AOO are $84 \mathrm{~km}^{2}$ (1.9\% of SCPA area), and $12 \mathrm{~km}^{2}(0.2 \%$ of SCPA area), respectively. This very small geographical range makes the conservation status of the two species very challenging, as it does not guarantee the survival of the species if it is threatened by a strong threat. Many scientists [8], [9], 13], [34], [35], [82] concluded that the probability of extinction for endemic species with narrow distribution ranges is significantly higher than for similar species with a larger distribution range.

The two species reported at altitudinal gradients range from 900 to $2350 \mathrm{~m}$, with the highest frequency for Silene leucophylla from 1800 to $2100 \mathrm{~m}$, and S. oreosinaica from 2000 to $2350 \mathrm{~m}$. A study by Omar [56] revealed that the elevation gradient is a controlling factor in the distribution of 
endemic species within the SCPA, and also that endemic plant species are more prevalent at elevations between 1200 to $2200 \mathrm{~m}$. Numerous investigations have demonstrated that endemism increases with increasing elevation [83]-[85]. Colwell \& Lees [86] pointed out that the distribution of plants in the mountainous highlands is governed by several factors that interfere with each other, whether biological, environmental or historical. As a result of the elevation shift, the climate in the region changes, as do the soil characteristics, resulting in a change in the composition and richness of plant variety [87]. The two target species with other 15 endemic species to SCPA (more than 30\% of Egypt endemics) are overlapped with each other in High Mountains Area, that makes SCPA the central of plant endemism as stated by Zohary [88] and McNeely et al. [89].

Considering topography as a role in the regulation dispersal, especially in mountainous areas, it has been recorded that Silene leucophylla are distributed in all aspects except South, and flat with most frequent in Northeast (29\%) and North (24\%). While S. oreosinaica recorded only in aspects North, Northeast, Northwest and East with most frequent in North (57\%) and Northeast (28\%). The two species have not been recorded in the south-facing aspect. According to Castellano et al. [90], the water relations of the soil and temperature are strongly impacted by the degree of mountain slope and aspect direction. It was discovered that the steep slopes facing south are hotter and drier than those facing north, which had lower temperatures and higher moisture content. The two species have been found to be primarily restricted to mountain slopes, namely deep mountain fissures with granite rocky ground. Within the study area, several studies have emphasized the specificity of micro-habitat are governed by factors such as elevation gradient [8], [9], [61], [91], slope ratio, aspect direction, solar radiation, and other factors that change the climatic structure of the area and thus affect the pattern of species distribution. Variation in soil prosperity in this study may be attributed to topography, slopes, and plant composition, which is consistent with Schlesinger et al. [92], Dunkerley \& Brown [93], Omar [56], and Shaltout et al. [91]. According to Abd El-Wahab et al. [94], the most significant variables influencing soil nutrient availability and regulation of vegetation covering and structure include elevation, soil physical structure, $\mathrm{pH}, \mathrm{EC}$, water retention, and organic matter.

Drought are the main threat to the target species, Zahran $e t$ al. [36] during field visits to study some endemic species within SCPA, state that some species are characterized by low seed composition and low seedling survival due to a number of factors, including natural and human activity. This conclusion was supported by several authors [8], [9], [95], [96], who emphasized that endemic plants in the area are subject to devastating threats, whether from drought and water scarcity, as well as overgrazing, and collection for treatment and commercial purposes, and over-collection for scientific research purposes. As these threats lead to a significant deterioration in the distribution of the plant and thus increase the risk of extinction. Target species distribution in mountain ecosystems has been documented to be fragmented, particularly in intra-mountain wadis and highaltitude ridges, where the physical formation of the mountain barrier to gene flow and causes lengthy isolated subpopulations, as Penningtona et al. [97] and Särkinen et al. [98] concluded.

The most appropriate habitat for Silene leucophylla was predicted to be in the northern, northeastern sections of SCPA, with the maximum suitability in the high mountains and Serbal areas, and its range is very fragmented as a consequence of mountain barriers. The scenario was different in the $S$. oreosinaica model, which was bigger and more fragmented. (This result may be contrary to reality, where the plant occupies a very small area representing only 3 subpopulations distributed over a very small area, which may cause a false prediction range and a wider range than normal. To avoid this, work must be done on increasing the number of coordinates points used in the analysis for a better and more accurate extraction). Confirming our results, the previous studies that have used the SDM for predicting the suitable habitat in SCPA conclude that endemic species are located in High Mountains Area [8], [9], [26], [27].

The current study confirmed that the use of SDM is useful for poorly-data species. However, the output prediction model does not confirm the presence of the species in the area. In S. oreosinaica, for example, the maxent model has given us a broad range of habitat suitability due to the lack of field records (only 20 points distributed in 3 main sites), which could not be true on the ground. As a result, it is critical that the data obtained in the field differ from the projected data retrieved from SDM. Given the limited resources available for SCPA management, the distribution data collected on the ground should serve as a foundation for determining investment priorities in conservation measures. However, SDM is still useful since data may be utilized in the future to study new regions based on their improved habitat suitability, which is in full accordance with what Langhammer et al. [99] determined.

In our study, precipitation of driest quarter, and precipitation of coldest quarter are the most important environmental variables for Silene leucophylla, while, precipitation of driest quarter, and mean temperature of driest quarter are the most important for S. oreosinaica. This result makes sense as the precipitation especially in mountain ecosystem affect the distribution of plant species. SCPA receives an annual average rainfall of 35 to $55 \mathrm{~mm}$ in the high mountains area, and Zohary [88] and Moustafa \& Zayed [100] determined that rain moisture is among the most important variables in limiting plant dispersion in this arid region. This combination strongly supports the presence and isolation of the desert's rarest plant species.

Unfortunately, Pavlik [101] has found that in many nations, recovery initiatives have failed to reach their goals due to a lack of data on the distribution of endangered species. Which was the study's goal to avoid. As a result, gathering field data, finding, and evaluating gaps in IUCN Red List evaluation programs is a key research goal in any country seeking to avert species extinction. We agree with Rodrigues et al. [102], Omar and Elgamal [8], and [9] that the data collected by the IUCN Red List Assessment tool (distribution, population status, habitats, ecological status, threats, conservation measures, etc.) is a powerful input to filling in the gaps in conservation development strategies. In this study, we have filled the gaps in the data needed for 
conservation planning operations (especially spatial data) where it was found that the two plants were at risk of extinction (Critically Endangered in the case of Silene oreosinaica and Endangered in the case of S. leucophylla) due to the small, restricted range.

Based on IUCN Standards and Petitions Committee [16], EOO, AOO, and population characteritics Silene leucophylla could be listed as Endangered (EN) under criteria B1ab $(\mathrm{i}, \mathrm{ii}, \mathrm{iii})+2 \mathrm{ab}(\mathrm{i}, \mathrm{ii}, \mathrm{iii})$. While Silene oreosinaica qualifies as Critically Endangered (CR) under category B1ab (ii,iii) + 2ab (ii,iii). The two species located in only two locations, the population is severely fragmented, and there is decline in habitat quality of this species in agreement with Omar [41][45], and Omar \& Elgamal [8], [9] who confirmed that there is a steady reduction in the number of species and the quality of habitat for endemic plant species in SCPA. Furthermore, climate change is expected to limit this high-elevation specialist's accessible habitat even further.

SCPA contains the global distribution of the two species. Every year, the SCPA team conducts thirty-foot patrols to monitor the present state of endemic plants in the high mountains region, with the goal of monitoring risks and finding ways to minimize or eliminate them. SCPA management team also implements education and awareness programs for the local population, stakeholders, and partners in the region. According to Omar [41]-[45], Omar \& Elgamal [8], [9], and Valderrábano et al. [40], there is a need to strengthen vulnerable species in situ and ex situ conservation initiatives, as well as focused management, recovery, and reintroduction activities at the species and population levels. Encouragement of community involvement and participatory techniques can help to properly understand traditional beliefs and practices, as well as successfully conserve plants and reduce pressures on plants in the wild.

\section{CONCLUSION}

We used IUCN Red List Categories and Criteria to estimate the extinction risk of Silene oreosinaica and $S$. leucophylla, which are endemic to St. Catherine Protected Area in south Sinai, Egypt. After gathering and evaluating data on geographical distribution, population status, habitat/ecology, and threats, they classified the species as Critically Endangered and Endangered. Despite the data obtained in this study, the conservation effort needs more. These species' research needs continue in the areas of genetic diversity between documented subpopulations, population trends, threat effect, validation of habitat suitability models, reproduction, and so on. The information derived from this study (tables, figures, etc.) can be utilized to launch effective future conservation programs. Due to the threat of grazing and drought to both species, and the possibility of collection for scientific research purposes in the near future, the importance of conservation of the two species through in situ (fenced enclosures, rehabilitation and reintroduction) and collection and storage of ex situ seeds in national seed banks was highlighted during field studies. It would be beneficial to establish grazing management in the high mountains. If SCPA employs traditional legislation for the local community, the conservation of the target species will be aided. It will be critical to raise environmental awareness among beneficiaries, whether they are locals, partners, universities, or research organizations, about the need of conserving unique species.

\section{AUTHOR CONTRIBUTIONS}

K.O. conceived of the presented idea, developed the theory, methodology, and performed the geographical and statistical analysis. I.E. collected the data from the field, verified the taxonomic characteristics of the targets species, K.O. and I.E. verified the analytical methods. K.O. wrote the original draft preparation. All authors discussed the results and contributed to the final draft.

\section{DECLARATION OF COMPETING INTEREST}

The authors have no conflict of interest.

\section{ACKNOWLEDGMENT}

The authors provide the best meanings of thanks and appreciation for the Conservation Leadership Programme (CLP) for their financial support in carrying out field survey activities. The authors also are grateful to Mr. Amir Shalouf, Mrs. Fatma Abdelbaset and professional Bedouin guides Seleim Mehana and Attia Soliman for their hard work within our fieldwork in SCPA. The first author dedicates this research to the soul of his father-inlaw, "Mr. Mohamed Koraym" who supported him to complete it and wished to see it. The second author also dedicates the benefit of the results of this research to the soul of his mother, who supported him throughout her life.

\section{REFERENCES}

[1] Pimm, S. L., Russell, G. J., Gittleman, J. L., \& Brooks, T. M. (1995) The future of biodiversity. Science, 269(5222), 347-350.

[2] Le Roux, J. J., Hui, C., Castillo, M. L., Iriondo, J. M., Keet, J.-H., Khapugin, A. A., Médail, F., Rejmánek, M., Theron, G., \& Yannelli, F. A. (2019). Recent anthropogenic plant extinctions differ in biodiversity hotspots and coldspots. Current Biology, 29(17), 2912 2918.

[3] Meyer, C., Weigelt, P., \& Kreft, H. (2016). Multidimensional biases, gaps and uncertainties in global plant occurrence information. Ecology Letters, 19(8), 992-1006. https://doi.org/10.1111/ele.12624.

[4] Sporbert, M., Bruelheide, H., Seidler, G., Keil, P., Jandt, U., Austrheim, G., Biurrun, I., Campos, J. A., Čarni, A., Chytrý, M., Csiky, J., De Bie, E., Dengler, J., Golub, V., Grytnes, J.-A., Indreica, A., Jansen, F., Jiroušek, M., Lenoir, J., Welk, E. (2019). Assessing sampling coverage of species distribution in biodiversity databases. Journal of Vegetation Science, 30(4), 620-632. https://doi.org/10.1111/jvs.12763.

[5] Ceballos, G., Ehrlich, P. R., Barnosky, A. D., García, A., Pringle, R. M., \& Palmer, T. M. (2015). Accelerated modern human-induced species losses: Entering the sixth mass extinction. Science Advances, 1(5), e1400253.

[6] He, F. (2009). Price of prosperity: economic development and biological conservation in China. Journal of Applied Ecology, 511515.

[7] Silveira, F. A. O., Teixido, A. L., Zanetti, M., Pádua, J. G., De Andrade, A. C. S., \& Da Costa, M. L. N. (2018). Ex situ conservation of threatened plants in Brazil: A strategic plan to achieve target 8 of the global strategy for plant conservation. Rodriguesia, 69(4), 1547-1555. https://doi.org/10.1590/2175-7860201869405.

[8] Omar, K., \& Elgamal, I. (2021a). Can we save critically endangered relict endemic plant species? A case study of Primula boveana Decne ex Duby in Egypt. Journal for Nature Conservation, 61, 126005.

[9] Omar, K., \& Elgamal, I. (2021b). IUCN Red List and Species Distribution Models as tools for the conservation of poorly known 
species: a case study of endemic plants Micromeria serbaliana and Veronica kaiseri in South Sinai, Egypt. Kew Bulletin, 1-20.

[10] Miller, R. M., Rodríguez, J. P., Aniskowicz-Fowler, T., Bambaradeniya, C., Boles, R., Eaton, M. A., Gärdenfors, U., Keller, V., Molur, S., \& Walker, S. (2006). Extinction risk and conservation priorities. Science, 313(5786), 441.

[11] Miller, R. M., Rodríguez, J. P., ANISKOWICZ-FOWLER, T., Bambaradeniya, C., Boles, R., Eaton, M. A., Gärdenfors, U. L. F., Keller, V., Molur, S., \& Walker, S. (2007). National threatened species listing based on IUCN criteria and regional guidelines: current status and future perspectives. Conservation Biology, 21(3), 684-696.

[12] Miller, R. M. (2013). Threatened species: Classification systems and their applications. In Encyclopedia of Biodiversity (pp. 191-210) Elsevier. https://doi.org/doi:10.1016/b978-0-12-384719-5.00415-9,

[13] Anderson, S. (1994). Area and endemism. The Quarterly Review of Biology, 69(4), 451-471.

[14] Payne, J. L., \& Finnegan, S. (2007). The effect of geographic range on extinction risk during background and mass extinction. Proceedings of the National Academy of Sciences, 104(25), 10506-10511.

[15] Fontaine, B., Bouchet, P., Van Achterberg, K., Alonso-Zarazaga, M. A., Araujo, R., Asche, M., Aspöck, U., Audisio, P., Aukema, B., \& Bailly, N. (2007). The European union's 2010 target: putting rare species in focus. Biological Conservation, 139(1-2), 167-185.

[16] IUCN Standards and Petitions Committee. (2019). Guidelines for Using the IUCN Red List Categories and Criteria, Version 14. 1(August), 1-60.

[17] Lamoreux, J., Resit Akçakaya, H., Bennun, L., Collar, N. J., Boitani, L., Brackett, D., Bräutigam, A., Brooks, T. M., da Fonseca, G. A. B., Mittermeier, R. A., Rylands, A. B., Gärdenfors, U., Hilton-Taylor, C., Mace, G., Stein, B. A., \& Stuart, S. (2003). Value of the IUCN Red List. Trends in Ecology \& Evolution, 18(5), 214-215. https://doi.org/10.1016/S0169-5347(03)00090-9.

[18] de Grammont, P. C., \& Cuarón, A. D. (2006). An evaluation of threatened species categorization systems used on the American continent. Conservation Biology, 20(1), 14-27.

[19] Mace, G. M., Collar, N. J., Gaston, K. J., Hilton-Taylor, C., Akçakaya, H. R., Leader-Williams, N., Milner-Gulland, E. J., \& Stuart, S. N (2008). Quantification of extinction risk: IUCN's system for classifying threatened species. Conservation Biology, 22(6), 1424 1442. https://doi.org/10.1111/j.1523-1739.2008.01044.x.

[20] Vié, J.-C., Hilton-Taylor, C., Pollock, C., Ragle, J., Smart, J., Stuart, S., \& Tong, R. (2008). The IUCN Red List: a Key Conservation Tool. In The 2008 Review of The IUCN Red List of Threatened Species. IUCN Gland,

https://www.iucn.org/sites/dev/files/import/downloads/the_iucn_red_1 ist a key conservation tool_1.pd.

[21] Elith, J., Graham, C. H., Anderson, R. P., Ferrier, S., Guisan, A., Hijmans, R. J., Huettmann, F., Leathwick, J. R., Lehmann, A., \& Li, J. (2006). Novel methods improve prediction of species' distributions from occurrence data. Ecography 29: 129-151. Peterson AT, Phillips SJ, Richardson KS, Scachetti-Pereira R, Schapire RE, Soberón J., Williams $S$, Wisz MS, Zimmermann NE.

[22] Elith, J., \& Leathwick, J. R. (2009). Species Distribution Models: Ecological Explanation and Prediction Across Space and Time. Annual Review of Ecology, Evolution and Systematics, 40, 677-697. https://doi.org/10.1146/annurev.ecolsys.110308.120159.

[23] McSHEA, W. (2014). What are the roles of species distribution models in conservation planning? Environmental Conservation, 41(2), 93-96.

[24] Raxworthy, C. J., Martinez-Meyer, E., Horning, N., Nussbaum, R. A., Schneider, G. E., Ortega-Huerta, M. A., \& Peterson, A. T. (2003). Predicting distributions of known and unknown reptile species in Madagascar. Nature, 426(6968), 837-841.

[25] Rushton, S. P., Ormerod, S. J., \& Kerby, G. (2004). New paradigms for modelling species distributions? Journal of Applied Ecology, 41(2), 193-200.

[26] Khafagi, O., Hatab, E. E., \& Omar, K. (2011). Predicting the potential geographical distribution of Nepeta septemcrenata in Saint Katherine Protectorate, South Sinai, Egypt using Maxent. Academia Arena, 3(7), $45-50$

[27] Khafagi, O., Hatab, E. E., \& \& Omar, K. (2013). Ecological Niche Modeling As a Tool for Conservation Planning: Suitable Habitat for Hypericum sinaicum in South Sinai, Egypt. Universal Journal of Environmental Research and Technology., 2(6), 515-524.

[28] Irfan-Ullah, M., Amarnath, G., Murthy, M. S. R., \& Peterson, A. T. (2007). Mapping the geographic distribution of Aglaia bourdillonii Gamble (Meliaceae), an endemic and threatened plant, using ecological niche modeling BT - Plant Conservation and Biodiversity (D. L. Hawksworth \& A. T. Bull (eds.); pp. 343-351). Springer Netherlands. https://doi.org/10.1007/978-1-4020-6444-9_22.
[29] Ray, R., Gururaja, K. V., \& Ramchandra, T. V. (2011). Predictive distribution modeling for rare Himalayan medicinal plant Berberis aristata DC. Journal of Environmental Biology, 32(6), 725-730.

[30] Adhikari, D., Barik, S. K., \& Upadhaya, K. (2012). Habitat distribution modelling for reintroduction of Ilex khasiana Purk., a critically endangered tree species of northeastern India. Ecological Engineering, $40,37-43$.

[31] Kaky, E., \& Gilbert, F. (2019). Assessment of the extinction risks of medicinal plants in Egypt under climate change by integrating species distribution models and IUCN Red List criteria. Journal of Arid Environments, 170, 103988.

[32] Hughes, C., \& Eastwood, R. (2006). Island radiation on a continental scale: Exceptional rates of plant diversification after uplift of the Andes. Proceedings of the National Academy of Sciences, 103(27), 10334-10339. https://doi.org/10.1073/pnas.0601928103.

[33] Khafagi, O., Hatab, E. E., \& Omar, K. (2012). Challenges towards Hypericum sinaicum conservation in south Sinai, Egypt. Jordan Journal of Biological Sciences, 6(2), 116-126.

[34] Gaston, K. J. (1998). Rarity as double jeopardy. Nature, 394(6690), 229-230.

[35] Whittaker, R. J., \& Fernández-Palacios, J. M. (2007). Island biogeography: ecology, evolution, and conservation. Oxford University Press.

[36] Zahran, M. A., Wafaa, A. M., Samy, A. A., \& Omran, G. N. (2015). Endemic species in Sinai peninsula, Egypt, with particular reference to Saint Katherine protectorate: I-ecological features. J. Environ. Sci 44(4), 589-609.

[37] Carlquist, S. J. (1974). Island biology. Columbia University Press.

[38] Strid, A. (1986). The mountain flora of Greece with special reference to the Anatolian element. Proceedings of the Royal Society of Edinburgh, Section B: Biological Sciences, 89, 59-68.

[39] Shehata, A. A., \& Kamel, W. M. (2007). A contribution to the palynological studies of the endemic flora of Sinai, Egypt. Roczniki Akademii Rolniczej w Poznaniu. Botanika-Steciana, 11.

[40] Valderrábano, M., Gil, T., Heywood, V., \& de Montmollin, B. (eds. (2018). Conserving wild plants in the south and east Mediterranean region (Issue BOOK_B). Union internationale pour la conservation de la nature.

[41] Omar, K. (2014). Primula boveana. The IUCN Red List of Threatened

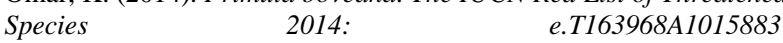
https://doi.org/10.2305/IUCN.UK.2014-

3.RLTS.T163968A1015883.en.

[42] Omar, K. (2017a). Bufonia multiceps. The IUCN Red List of Threatened Species 2017: e. T84119945A84119949.

[43] Omar, K. (2017a). Euphorbia obovata. The IUCN Red List of Threatened Species 2017: e. T84119968A84119977.

[44] Omar, K. (2017b). Phlomis aurea. The IUCN Red List of Threatened Species 2017: e. T84119983A84119987

[45] Omar, K. (2017c). Rosa arabica. The IUCN Red List of Threatened Species 2017: e. T84120072A84120074.

[46] Bratteler, M., Baltisberger, M., \& Widmer, A. (2006). QTL analysis of intraspecific differences between two Silene vulgaris ecotypes. Annals of Botany, 98(2), 411-419.

[47] Boulos, L. (2009). Flora of Egypt checklist, revised annotated edition. Al-Hadara Publishing, Cairo, 198-201.

[48] Radford, E. A., Catullo, G., \& and Montmollin, B. de. (eds). (2011). Important Plant Areas of the south and east Mediterranean region: priority sites for conservation. Gland, Switzerland and Malaga, Spain IUCN. (viii +). Gland, Switzerland and Malaga, Spain: IUCN https://portals.iucn.org/library/sites/library/files/documents/2011014.pdf.

[49] Rabei, S., Nada, R., \& El Gamal, I. (2016). Bio-systematic study on the endemic Silene oreosinaica Chowdhuri from Sinai, Egypt. Scientific Journal for Damietta Faculty of Science, 6(2), 183-188.

[50] Boulos, L. (1999). Flora of Egypt, vol. 1. Cairo: Al Hadara Publishing, 417.

[51] El Hadidi, M. N., \& Hosni, H. A. (2000). Flora Aegyptiaca: part 1-vol. 1, part 2. Palm Press.

[52] Hosny, A. I., El Hadidi, M. N., \& Shamso, E. M. (1992). Taxonomic Studies of Silenoideae (Cartophyllaceae) in Egypt. 1. Systematic revision of the genus Silene L. Taeckholmia, 14, 1-36.

[53] Rabei, S., Nada, R., \& EL Gamal, I. (2020). Studies on five Silene L. Taxa in Saint Catherine Protectorate, South Sinai, Egypt. Jordan Journal of Biological Sciences, 13(1), 59-67.

[54] Täckholm, V. (1974). Students' Flora of Egypt. -Cairo University press, Cairo.

[55] Moustafa, A. A., \& Klopatek, J. M. (1995). Vegetation and landforms of the Saint Catherine area, southern Sinai, Egypt. Journal of Arid Environments, 30(4), https://doi.org/https://doi.org/10.1006/jare.1995.0033. 
[56] Omar, K. (2012). Vegetation, soil and grazing analysis in Saint Katherine Protectorate, South Sinai, Egypt. NeBIO, 3(2), 80-92.

[57] Hatab, E. E. (2009). Ecological studies on the Acacia Species and Ecosystem Restoration in the Saint Katherine Protectorate, South Sinai, Egypt. Al-Azhar University.

[58] Fayed, A. A., El-Garf, I. A., Abdel-Khalik, K. N., \& Osman, A. K. (2004). Floristic survey of the mountainous region of South Sinai, St Katherine's Protectorate, Medicinal Plants Conservation Project. Egypt, Report, 146.

[59] Shaltout, K., Heneidy, S., Al-Sodany, Y., M., M., Eid, E., Hatim, M., \& E., E.-G. (2004). Floristic Survey of the Mountainous Region of South Sinai; St. Katherine's Protectorate, Medicinal Plants Conservation Project. Egypt.

[60] Moustafa, A. A., Zaghloul, M. S., El-Wahab, R. H. A., \& Shaker, M (2001). Evaluation of plant diversity and endemism in Saint Catherine Protectorate, South Sinai, Egypt. Egyptian Journal of Botany, 41(1), $121-139$

[61] Khedr, A. (2007). Assessment, classification, and analysis of microhabitats supporting globally significant plant species. Conservation and Sustainable Use of Medicinal Plants in Arid an Semi-Arid Eco-Systems Project. Saint Katherine Protectorate, Egypt, Final Report: EEAA, GEF \& UNDP, Cairo, Egypt, 145.

[62] Cox, G. (1990). Laboratory manual of general ecology 6th Ed Dubuque, Iowa: WIlliam C. Brown, 143 pp.

[63] IUCN. (2012). IUCN Red List Categories and Criteria: Version 3.1. Second edition. In Gland, Switzerland and Cambridge, UK: IUCN.: Vol. iv. https://portals.iucn.org/library/node/10315.

[64] Jackson, M. L. (1967). Soil chemical analysis. Prentice Hall of India Pvt. Ltd., New Delhi, 498 p.

[65] Braun-Blanquet, J. (1964). Plant sociology. Translated by GD Fuller and HS Conard Mc-Graw-Hill Book Co. Inc. New York, 865.

[66] Assi, R. (2007). MP Threat Analysis and Threat Reduction Assessment Report. In Conservation and sustainable use of medicinal plants in arid and semi-arid ecosystems project.

[67] Kumar, S., Stohlgren, T. J., \& Chong, G. W. (2006). Spatial heterogeneity influences native and nonnative plant species richness. Ecology, 87(12), 3186-3199. https://doi.org/10.1890/0012 9658(2006)87[3186:SHINAN]2.0.CO;2.

[68] Guisan, A., Graham, C. H., Elith, J., Huettmann, F., \& Group, N. S. D. M. (2007). Sensitivity of predictive species distribution models to change in grain size. Diversity and Distributions, 13(3), 332-340.

[69] Pearson, R. G., Raxworthy, C. J., Nakamura, M., \& Townsend Peterson, A. (2007). Predicting species distributions from small numbers of occurrence records: A test case using cryptic geckos in Madagascar. Journal of Biogeography, 34(1), 102-117. https://doi.org/10.1111/j.1365-2699.2006.01594.x.

[70] Hijmans, R. J., Cameron, S. E., Parra, J. L., Jones, P. G. \&, \& Jarvis, A. (2005). Very high resolution interpolated climate surfaces for global land areas. International Journal of Climatology: A Journal of the Royal Meteorological Society, 25(15), 1965-1978

[71] Graham, C. H., \& Hijmans, R. J. (2006). A comparison of methods for mapping species ranges and species richness. Global Ecology and Biogeography, 15(6), 578-587.

[72] Murienne, J., Guilbert, E., \& Grandcolas, P. (2009). Species' diversity in the New Caledonian endemic genera Cephalidiosus and Nobarnus (Insecta: Heteroptera: Tingidae), an approach using phylogeny and species' distribution modelling. Biological Journal of the Linnean Society, 97(1), 177-184. https://doi.org/10.1111/j.10958312.2008.01184.x

[73] de Luis, M., Bartolomé, C., García Cardo, Ó., \& Álvarez-Jiménez, J. (2018). Gypsophila bermejoi G. López: A possible case of speciation repressed by bioclimatic factors. PloS One, 13(1), e0190536.

[74] Bosso, L., Di Febbraro, M., Cristinzio, G., Zoina, A., \& Russo, D (2016). Shedding light on the effects of climate change on the potentia distribution of Xylella fastidiosa in the Mediterranean basin. Biological Invasions, 18(6), 1759-1768.

[75] Smeraldo, S., Di Febbraro, M., Bosso, L., Flaquer, C., Guixé, D., Lisón, F., Meschede, A., Juste, J., Prüger, J., \& Puig-Montserrat, X. (2018) Ignoring seasonal changes in the ecological niche of non-migratory species may lead to biases in potential distribution models: lessons from bats. Biodiversity and Conservation, 27(9), 2425-2441.

[76] Kalle, R., Ramesh, T., Qureshi, Q., \& Sankar, K. (2013). Predicting the distribution pattern of small carnivores in response to environmental factors in the Western Ghats. PLoS One, 8(11), e79295.

[77] Ortega-Huerta, M. A. ., \& Peterson, A. T. (2008). Modeling ecological niches and predicting geographic distributions: A test of six presenceonly methods. Revista Mexicana de La Biodiversidad, 1(1), 205-216.

[78] Hernandez, P. A., Graham, C. H., Master, L. L., \& Albert, D. L. (2006). The effect of sample size and species characteristics on performance of different species distribution modeling methods. Ecography, 29(5), 773-785.

[79] Papeș, M., \& Gaubert, P. (2007). Modelling ecological niches from low numbers of occurrences: Assessment of the conservation status of poorly known viverrids (Mammalia, Carnivora) across two continents. Diversity and Distributions, 13(6), 890-902. https://doi.org/10.1111/j.1472-4642.2007.00392.x.

[80] Hoveka, L., Bezeng, B., Yessoufou, K., Boatwright, J., \& Van der Bank, M. (2016). Effects of climate change on the future distributions of the top five freshwater invasive plants in South Africa. South African Journal of Botany, 102, 33-38.

[81] Choudhury, M. R., Deb, P., Singha, H., Chakdar, B., \& Medhi, M. (2016). Predicting the probable distribution and threat of invasive Mimosa diplotricha Suavalle and Mikania micrantha Kunth in a protected tropical grassland. Ecological Engineering, 97, 23-31. https://doi.org/10.1016/j.ecoleng.2016.07.018.

[82] Işik, K. (2011). Rare and endemic species: Why are they prone to extinction? Turkish Journal of Botany, 35(4), 411-417. https://doi.org/10.3906/bot-1012-90.

[83] Balslev, H. (1988). Distribution patterns of Ecuadorean plant species Taxon, 37(3), 567-577.

[84] Sklenář, P., \& Jørgensen, P. M. (1999). Distribution patterns of paramo plants in Ecuador. Journal of Biogeography, 26(4), 681-691. https://doi.org/10.1046/j.1365-2699.1999.00324.x.

[85] Kessler, M. (2000). Elevational gradients in species richness and endemism of selected plant groups in the central Bolivian Andes. Plant Ecology, 149(2), 181-193. https://doi.org/10.1023/A:1026500710274.

[86] Colwell, R. K., \& Lees, D. C. (2000). The mid-domain effect geometric constraints on the geography of species richness. Trends in Ecology \& Evolution, 15(2), 70-76.

[87] Brown, J. H. (2001). Mammals on mountainsides: elevational patterns of diversity. Global Ecology and Biogeography, 10(1), 101-109.

[88] Zohary, M. (1973). Geobotanical foundations of the Middle East. Stuttgart, G. Fischer.

[89] McNeely, J. A., Harrison, J., \& Dingwall, P. (1994). Protecting nature: Regional reviews of protected areas. In IVth world congress on national parks and protected areas, Caracas, Venezuela.

[90] Castellano, M. A., Trappe, J. M., \& Luoma, D. L. (2004) SEQUESTRATE FUNGI. In Biodiversity of Fungi (pp. 197-213). https://doi.org/10.1016/B978-012509551-8/50013-1.

[91] Shaltout, K., Ahmed, D. ., \& Shabana, H. . (2015). Population structure and dynamics of the endemic species Phlomis aurea Decne in different habitats in southern Sinai Peninsula, Egypt. Global Ecology and Conservation, 4, 505-515. https://doi.org/https://doi.org/10.1016/j.gecco.2015.10.002

[92] Schlesinger, W. H., Raikes, J. A., Hartley, A. E., \& Cross, A. F. (1996) On the Spatial Pattern of Soil Nutrients in Desert Ecosystems. Ecology, 77(2), 364-374. https://doi.org/10.2307/2265615.

[93] Dunkerley, D. L., \& Brown, K. J. (1997). Desert soils. Arid Zone Geomorphology: Process, Form and Change in Drylands'. 2nd Edn.(Ed. DSG Thomas.) pp. 55-68.

[94] Abd El-Wahab, R., \& Moustafa, A. (2006). Vegetation and Environment of Gebel Serbal, South Sinai, Egypt. Catrina, 1, 9-20.

[95] El-Demerdash, M. (2007). The Ex Situ Conservation Technical Report on Propagation of Medicinal Plants. MPCP, The Egyptian Environmental Affairs Agency (EEAA).

[96] El-Mawey, M. (2008). Technical Report on Restoration of Endangered Plant Species in St. Catherine Protectorate. MPCP, Egyptian Environmental Affairs Agency (EEAA).

[97] Pennington, R. T., Lavin, M., Särkinen, T., Lewis, G. P., Klitgaard, B. B., \& Hughes, C. E. (2010). Contrasting plant diversification histories within the Andean biodiversity hotspot. Proceedings of the National Academy of Sciences of the United States of America, 107(31), 1378313787. https://doi.org/10.1073/pnas.1001317107.

[98] Särkinen, T. E., Marcelo-Peña, J. L., Daza Yomona, A., Simon, M. F., Toby Pennington, R., \& Hughes, C. E. (2011). Underestimated endemic species diversity in the dry inter-Andean valley of the Río Marañón, northern Peru: An example from Mimosa (Leguminosae, Mimosoideae). Taxon, 60(1), 139-150. https://doi.org/10.1002/tax.601012

[99] Langhammer, P. F., Bakarr, M. I., Bennun, L. A., Brooks, T. M., Clay, R. P., Darwall, W., De Silva, N., Edgar, G. J., Eken, G., Fishpool, L. D. C., Fonseca, G. A. B. da, Foster, M. N., Knox, D. H., Matiku, P., Radford, E. A., Rodrigues, A. S. L., Salaman, P., \& Sechrest, W. A. W (2007). Identification and gap analysis of key biodiversity areas: targets for comprehensive protected area systems. In Gland, Switzerland: IUCN. Gland, Switzerland: IUCN. https://doi.org/10.2305/iucn.ch.2006.pag.15.en 
European Journal of Biology and Biotechnology www.ejbio.org

[100]Moustafa, A., \& Zayed, A. (1996). Effect of environmental factors on the flora of alluvial fans in southern Sinai. Journal of Arid Environments, 32(4), 431-443.

[101]Pavlik, B. M. (1997). Perspectives, Tools, and Institutions for Conserving Rare Plants. The Southwestern Naturalist, 42(4), 375-383. http://www.jstor.org/stable/30055302.

[102] Rodrigues, A. S. L., Pilgrim, J. D., Lamoreux, J. F., Hoffmann, M., \& Brooks, T. M. (2006). The value of the IUCN Red List for conservation. Trends in Ecology \& Evolution, 21(2), 71-76. https://doi.org/10.1016/j.tree.2005.10.010. 